\title{
Actinomycosis: etiology, clinical features, diagnosis, treatment, and management
}

This article was published in the following Dove Press journal:

Infection and Drug Resistance

5 July 2014

Number of times this article has been viewed

\author{
Florent Valour ${ }^{1-3}$ \\ Agathe Sénéchal ${ }^{1,2}$ \\ Céline Dupieux ${ }^{2-4}$ \\ Judith Karsenty ${ }^{1,2}$ \\ Sébastien Lustig ${ }^{2,5}$ \\ Pierre Breton ${ }^{2,6}$ \\ Arnaud Gleizal 2,7 \\ Loïc Boussel ${ }^{2,8,9}$ \\ Frédéric Laurent ${ }^{2-4}$ \\ Evelyne Braun' \\ Christian Chidiac ${ }^{1-3}$ \\ Florence Ader ${ }^{1-3}$ \\ Tristan Ferry ${ }^{1-3}$
}

'Service des Maladies Infectieuses et Tropicales, Hospices Civils de Lyon,

Groupement Hospitalier Nord, Lyon, France;

${ }^{2}$ Université Claude Bernard Lyon I, Lyon,

France; ${ }^{3}$ Centre International de Recherche en Infectiologie, CIRI, INSERM UI I I I, CNRS UMR5308, ENS de Lyon, UCBLI, Lyon,

France; ${ }^{4}$ Laboratoire de Bactériologie, Centre de Biologie du Nord, Hospices Civils de Lyon, Groupement Hospitalier Nord, Lyon, France;

${ }^{5}$ Chirurgie Orthopédique, Hospices Civils de Lyon, Groupement Hospitalier Nord, Lyon, France; ${ }^{6}$ Stomatologie et Chirurgie Maxillo-faciale, Hospices Civils de Lyon, Groupement Hospitalier Sud, Lyon, France; ${ }^{7}$ Chirurgie Maxillo-faciale, Hospices Civils de Lyon, Groupement Hospitalier Nord, Lyon, France; ${ }^{8}$ Radiologie, Hospices Civils de Lyon, Groupement Hospitalier Nord, Lyon, France; ${ }^{9} \mathrm{Creatis,}$ CNRS UMR 5220, INSERM UI044, Université Lyon I, INSA Lyon, Lyon, France

Correspondence: Tristan Ferry Service de Maladies Infectieuses et Tropicales, Hospices Civils de Lyon - Hôpital de la Croix-Rousse, 103, Grande-Rue de la Croix-Rousse,

69317 Lyon cedex 04, France

Tel +33472072481

Fax +3347207 I750

Email tristan.ferry@univ-lyon I.fr
Abstract: Actinomycosis is a rare chronic disease caused by Actinomyces spp., anaerobic Gram-positive bacteria that normally colonize the human mouth and digestive and genital tracts. Physicians must be aware of typical clinical presentations (such as cervicofacial actinomycosis following dental focus of infection, pelvic actinomycosis in women with an intrauterine device, and pulmonary actinomycosis in smokers with poor dental hygiene), but also that actinomycosis may mimic the malignancy process in various anatomical sites. Bacterial cultures and pathology are the cornerstone of diagnosis, but particular conditions are required in order to get the correct diagnosis. Prolonged bacterial cultures in anaerobic conditions are necessary to identify the bacterium and typical microscopic findings include necrosis with yellowish sulfur granules and filamentous Gram-positive fungal-like pathogens. Patients with actinomycosis require prolonged (6- to 12-month) high doses (to facilitate the drug penetration in abscess and in infected tissues) of penicillin $\mathrm{G}$ or amoxicillin, but the duration of antimicrobial therapy could probably be shortened to 3 months in patients in whom optimal surgical resection of infected tissues has been performed. Preventive measures, such as reduction of alcohol abuse and improvement of dental hygiene, may limit occurrence of pulmonary, cervicofacial, and central nervous system actinomycosis. In women, intrauterine devices must be changed every 5 years in order to limit the occurrence of pelvic actinomycosis.

Keywords: Actinomyces spp., sulfur granule, osteomyelitis, lumpy jaw syndrome

\section{Introduction}

Actinomycosis is an infrequent invasive bacterial disease that has been recognized for over a century. Actinomyces spp. are filamentous Gram-positive bacilli, mainly belonging to the human commensal flora of the oropharynx, gastrointestinal tract, and urogenital tract. To date, multiple different clinical features of actinomycosis have been described, as various anatomical sites (such as face, bone and joint, respiratory tract, genitourinary tract, digestive tract, central nervous system, skin, and soft tissue structures) can be affected. Of note, in any site, actinomycosis frequently mimics malignancy, tuberculosis, or nocardiosis, as it spreads continuously and progressively, and often forms a cold abscess. $^{1-3}$

In this review, we aim to describe: 1) the overview of the different species of Actinomyces; 2) their involvement in different clinical features with illustrative cases; and 3) key elements for the diagnosis, ie, bacterial cultures and pathology; and 4) current and emerging treatment options. 


\section{Overview of the different species of Actinomyces bacteria that cause actinomycosis}

Bacteria of the genus Actinomyces belong to the Actinobacteria phylum and Actinomycetales order and are related to other genera such as Corynebacterium, Mycobacterium, Nocardia, and Propionibacterium. Besides Actinomyces, Propionibacterium propionicum (formerly Arachnia propionica), has often been reported as an agent of actinomycosis-like infections., ${ }^{2,4}$ More than 30 species of Actinomyces have been described. Actinomyces israelii is the most prevalent species isolated in human infections and is found in most clinical forms of actinomycosis. ${ }^{1-3,5,6}$ Actinomyces viscosus and Actinomyces meyeri are also often reported in typical actinomycosis, although they are less common, ${ }^{6,7}$ and $A$. meyeri is considered to have a great propensity for dissemination. Some species, including Actinomyces naeslundii, Actinomyces odontolyticus, Actinomyces gerencseriae (formerly A. israelii serotype 2), Actinomyces neuii, Actinomyces turicensis, and Actinomyces radingae, have been associated with particular clinical syndromes. ${ }^{8-11}$ Thus, A. israelii and A. gerencseriae are responsible for about $70 \%$ of orocervicofacial infections. ${ }^{5}$ Hematogenous dissemination of actinomycosis is extremely rare and has mainly been associated with $A$. meyeri, A. israelii, and A. odontolyticus. ${ }^{12}$ Of note, most of the Actinomyces spp. are present in polymicrobial flora. Therefore Actinomyces are often isolated with other normal commensals, such as Aggregatibacter actinomycetemcomitans, Eikenella corrodens, Capnocytophaga, fusobacteria, Bacteroides, staphylococci, streptococci, or Enterobacteriaceae, depending on the site of infection. ${ }^{4}$ As such, it is difficult to discriminate colonization of mucosa-contaminating samples and infection due to Actinomyces except when the culture is pure and associated with the presence of polynuclear neutrophils. On the other hand, Actinomyces infections could be polymicrobial and associated with other bacteria, named "companion microbes", which contribute to initiation and development of infection by inhibiting host defenses or reducing oxygen tension. ${ }^{3}$ The multimicrobial nature of infection is well described in animal models and in human cervicofacial actinomycosis. $^{13-15}$

\section{Microbiological diagnosis of actinomycosis}

The bacteriological identification of Actinomyces from a sterile site confirms the diagnosis of actinomycosis. However, isolation and identification of these causative bacteria occur in only a minority of cases; the failure rate of culture is high because of previous antibiotic therapy, inhibition of Actinomyces growth by concomitant and/or contaminant microorganisms, inadequate culture conditions, or inadequate short-term incubation. ${ }^{16}$ Because of the microaerophilic or strict anaerobic character of Actinomyces, strict anaerobic processing (rapid transport to the laboratory and/or transport in an anaerobic transport medium) and anaerobic growth conditions should be used for primary isolation. The most appropriate clinical specimens are tissue from surgical biopsy or pus; swabs must be avoided. Finally, clinicians should indicate suspicion for actinomycosis to the microbiologist to ensure that prolonged culture on appropriate media and in an appropriate atmosphere is performed. Moreover, the identification of Actinomyces in mucosa, where these bacteria are normal inhabitants, is of little significance in the absence of sulfur granules (see "Pathology of actinomycosis") or a typical clinical syndrome, highlighting the importance of microbiological investigations in combination with histologic analysis.

A Gram stain of the specimen is usually more sensitive than culture, especially if the patient had received antibiotics. Actinomyces are non-spore-forming Gram-positive rods. Except for A. meyeri, which is small and nonbranching, all the other species are branching filamentous rods.

Growth of Actinomyces is slow; it appears within at least 5 days and may take up to 15-20 days. Thus, incubation of at least 10 days is required before conclusion of a negative culture. Most Actinomyces spp. are facultative anaerobes, but some relevant species (such as A. meyeri), are strictly anaerobic, so cultures must be incubated in an anaerobic atmosphere. Actinomyces can be cultured on chocolate blood agar media at $37^{\circ} \mathrm{C}$. Other enriched media can be used for Actinomyces isolation: brain heart infusion broth and Brucella Blood Agar with hemin and vitamin K1. The use of semi-selective media (such as phenylethyl alcohol or mupirocin-metronidazole blood agar) may increase isolation rates by inhibiting overgrowth of concomitant organisms. ${ }^{17}$ Actinomyces can be initially suspected by colony morphology and biochemical profiling. For example, A. israelii forms a "molar tooth" colony on agar and grows as clumps within broth, whereas $A$. odontolyticus forms rust-brown or red-colored colonies. Actinomyces are indole-negative bacteria. Identification was classically based on phenotypic tests (urease, catalase, fermentation of sugars, etc) or on commercial biochemical kits but, in fact, such tests can lead to misidentification of species and even of genus. ${ }^{18,19}$ Serological assays have been developed but need to be improved before they become clinically useful. 
The classification of Actinomyces spp., initially based on phenotypic characters, has been recently revised, due to advances in microbiological taxonomy that use genotypic methods such as comparative $16 \mathrm{~S}$ ribosomal RNA (rRNA) gene sequencing. Therefore, nowadays, molecular techniques such as $16 \mathrm{~S}$ rRNA sequencing serve as the reference for identification. ${ }^{11,20}$ Besides 16S rRNA sequencing, a practical identification method consists of $16 \mathrm{~S}$ ribosomal DNA restriction analysis. ${ }^{21}$ Polymerase chain reaction with specific primers can also be used for direct detection of Actinomyces in clinical material. ${ }^{22,23}$ Finally, matrix-assisted laser desorption ionization time-of-flight (MALDI-TOF) should be a quicker and accurate tool for Actinomyces identification in the future. Mass spectrometry uses an ionization source to charge and separate ionized bacterial proteins; then, a detector and mass analyzer generate a mass spectrum specific to bacterial species. Concerning Actinomyces, MALDI-TOF allows accurate identification at the genus level, but species identification remains uncertain and depends on the mass spectrometry system and the species studied. ${ }^{18,20}$ Improvement of this technique is needed for a definitive identification of Actinomyces spp., but it so far seems very promising.

\section{Pathology of actinomycosis}

Gram staining of pus and pathology of infected tissue is of great interest for the diagnosis of actinomycosis, as it is usually more sensitive than culture, which remains sterile in more than $50 \%$ of cases. Once Actinomyces spp. have invaded tissues, they develop a chronic granulomatous infection characterized by the formation of tiny clumps, called sulfur granules because of their yellow color. These formations of $0.1-1 \mathrm{~mm}$ in diameter, composed of an internal tangle of mycelial fragments and a rosette of peripheral clubs, are stabilized by a protein-polysaccharide complex, which is supposed to provide a resistance mechanism to host defenses by inhibiting phagocytosis. ${ }^{24-27}$ Histopathology examination discloses one to three sulfur granules in about $75 \%$ of cases, described as basophilic masses with eosinophilic terminal clubs on staining with hematoxylin and eosin (see "Case 8"). ${ }^{16}$ Typical microscopic findings include necrosis with yellowish sulfur granules and filamentous Gram-positive fungal-like pathogens. Yellowish sulfur granules are constituted by conglomeration of bacteria trapped in biofilm. ${ }^{28}$

These findings are highly suggestive of the diagnosis but are not specific, as they can be encountered in other pathogenic conditions such as nocardiosis or chronic cervicofacial fungal infections. However, Gram staining can additionally show Gram-positive filamentous branching bacteria at the periphery of the granule that is highly suggestive of actinomycosis. Immunofluorescence techniques have poor sensitivity but are highly specific in the diagnosis.

\section{Drug susceptibility of Actinomyces spp.}

Drug resistance is not considered a problem in actinomycosis. Indeed, Actinomyces spp. are usually extremely susceptible to beta-lactams, and especially penicillin $\mathrm{G}$ or amoxicillin. As a consequence, penicillin $\mathrm{G}$ or amoxicillin are considered drugs of choice for the treatment of actinomycosis. Third-generation cephalosporins are less frequently used even if they are considered to be active on $A$. israelii; however, it is important to note that some species are resistant to ceftriaxone (Actinomyces europaeus and Actinomyces graevenitzii). ${ }^{1-3,29}$ Piperacillin-tazobactam, imipenem, and meropenem are considered to be active, but the use of these broad-spectrum antibiotics should be limited to avoid acquisition of resistant flora. Oxacillin, cloxacillin, and cephalexin, a first-generation cephalosporin, are not considered to be active. Metronidazole and aminoglycosides have no in vitro activity against Actinomyces. Fluoroquinolones (ciprofloxacin and moxifloxacin) are usually considered to be inactive, but data are limited and controversial. Doxycycline is considered to have a poor activity on Actinomyces spp., but clinical successes have been reported with this drug. Macrolides and clindamycin have been used successfully as alternatives. As Actinomyces spp. do not produce beta-lactamases, it is not useful to combine amoxicillin with beta-lactam inhibitors such as clavulanic acid, except if co-pathogens such as Enterobacteriaceae are involved in the disease. ${ }^{1-3,29}$

\section{Clinical features of actinomycosis Respiratory tract actinomycosis Epidemiology and pathogenesis}

Respiratory tract actinomycosis includes pulmonary, bronchial, and laryngeal actinomycosis. Pulmonary actinomycosis is the third most common type of actinomycosis, after that occurring in cervicofacial and abdominopelvic locations. In children, pulmonary involvement is uncommon. ${ }^{30}$ The peak incidence is reported to be in the fourth and fifth decades of life. ${ }^{31,32}$ Males are more often affected than women, with a 3:1 ratio. ${ }^{16}$ Pulmonary actinomycosis results mainly from aspiration of oropharyngeal or gastrointestinal secretions. ${ }^{31}$ Consequently, individuals with poor oral hygiene, preexisting dental disease, and alcoholism have an increased risk for developing pulmonary actinomycosis. ${ }^{24,33}$ Otherwise, patients with chronic lung 
disease such as emphysema, chronic bronchitis, and bronchiectasis, and patients with pulmonary sequelae following tuberculosis, are considered to also be at risk for pulmonary actinomycosis. ${ }^{30}$ The mechanism of immune response in actinomycosis remains unclear, but some factors, by altering this response, probably promote the disease. Human immunodeficiency virus infection, steroid use, infliximab treatment, lung and renal transplantation, and acute leukemia during chemotherapy have been described as risk factors, despite few data being available in such patients (see “Case 1").3,34,35

At early stages of the disease, a focal pulmonary consolidation occurs, which can be surrounded by pulmonary nodules, but there are often no associated physical symptoms at this stage. This primary pulmonary involvement could secondly lead to constitution of a peripheral mass, with or without cavitation, which could invade adjacent tissue. ${ }^{36,37}$ At this stage, pulmonary actinomycosis is usually characterized by fibrotic lesion with slow contiguous growth passing through the anatomical barriers. ${ }^{24}$ The mass is often confused with malignancy.

A direct or indirect extension from cervicofacial infection to the thorax may also lead to pulmonary actinomycosis (see "Case 1"). Conversely, pulmonary actinomycosis could be associated with extrapulmonary spread, from the lung to the pleura, mediastinum, and chest wall, with fistula and chronic suppuration (see "Case 2"). ${ }^{35}$ Finally, hematogenous dissemination with pulmonary location has been observed in patients with disseminated actinomycosis..$^{2,24}$ Pulmonary actinomycosis can also be detected in children without any risk factor for the disease, and the most common presentation is a chest wall mass. ${ }^{36}$

Bronchial actinomycosis is rare. It may occur after disruption of the mucosal barrier, especially in patients with endobronchial stent, or with a bronchial foreign body aspiration (for example, of a fish bone). ${ }^{3,37,38}$

Concerning laryngeal actinomycosis, various different forms have been described. Vocal cord actinomycosis may mimic primary carcinoma or papilloma, whereas in patients with past history of laryngeal carcinoma and radiotherapy, actinomycosis may mimic laryngeal cancer relapse, as it may present as an ulcerative lesion, most often without abscess or sinus tract. ${ }^{39,40}$

\section{Illustrative case reports \\ Case I}

A 37-year-old woman presented with a 5-month history of chronic sinusitis without fever 1 year after allogeneic allograft bone marrow transplant for idiopathic aplasia. Computed tomography (CT) scan revealed right maxillary sinusitis and left focal basal pneumonia, without cavitation (Figure 1). Bronchoalveolar fluid (BAL) revealed Actinomyces spp. in culture. The patient responded well to right maxillary antrostomy and high doses of intravenous and then oral amoxicillin for 5 months.

\section{Case 2}

A 53-year-old man with long-term tobacco and alcohol abuse was admitted for asthenia and loss of $20 \mathrm{~kg}$ in 6 months. The patient had had a cough for several months, but never experienced hemoptysis. Physical examination revealed a right pulmonary crackling sound. A sinus tract, which followed a 3-week history of subcutaneous abscess, was observed in the right face of the thorax. Chest X-ray and CT scan revealed multifocal pneumonia with right pleural cavitation, in the face of the sinus tract (Figure 2). Magnetic resonance imaging (MRI) revealed contiguous thoracic spine involvement,
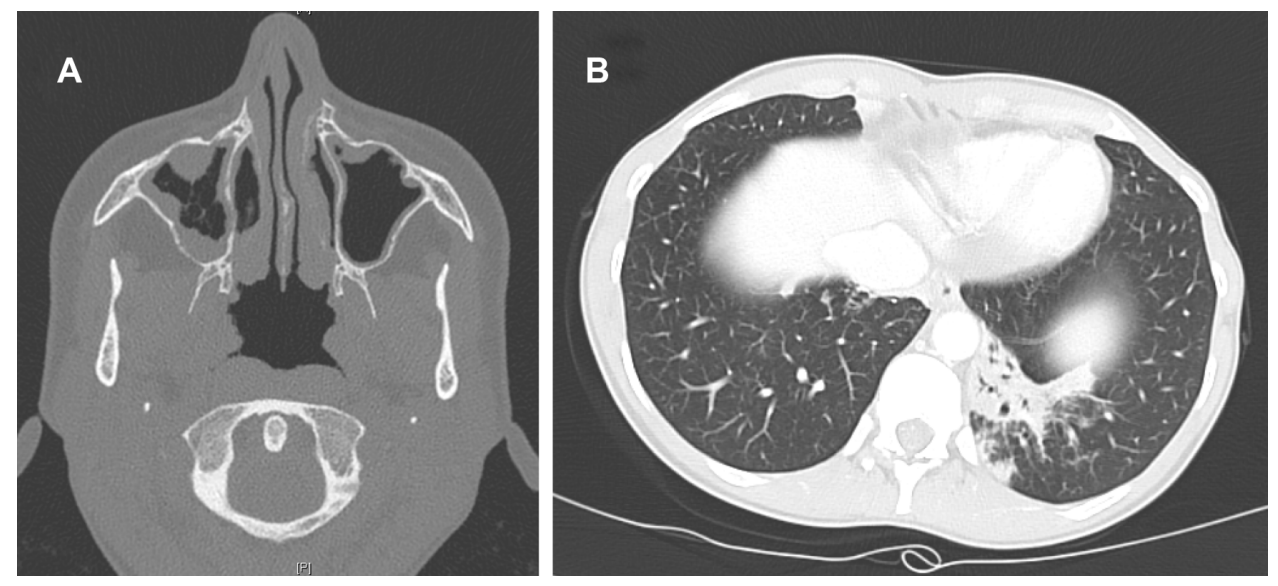

Figure I Computed tomography scan revealing a right maxillary sinusitis (A) and left focal basal pneumonia without cavitation (B), due to Actinomyces spp., in an immunosuppressed woman. 


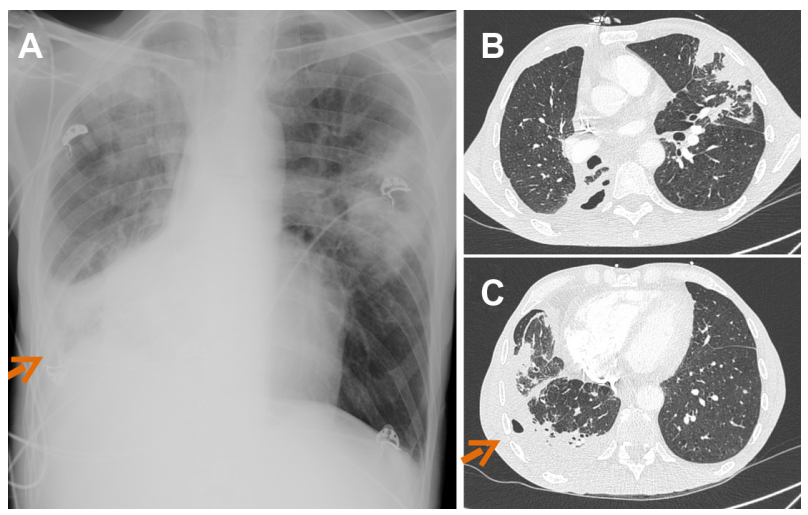

Figure 2 Chest $\mathrm{X}$-ray $(\mathbf{A})$ and thorax computed tomography scan (B-C) revealing multifocal pneumonia with right pleural cavitation due to Actinomyces viscosus. Note: Arrows indicate chest wall sinus tract.

with paravertebral abscess (see "Extrafacial bone and joint actinomycosis"). BAL revealed $A$. viscosus in culture. The patient responded well to prolonged amoxicillin therapy (9 months).

\section{Signs and symptoms}

Pulmonary actinomycosis could be acute or subacute, with lobar pulmonary involvement. However, the disease is mostly diagnosed at the chronic phase, in patients presenting mild fever and weight loss. The most common symptoms are nonspecific, similar to those of other chronic lung infections such as tuberculosis or thoracic cancer: productive cough, hemoptysis, dyspnea, and chest pain. ${ }^{41}$ General symptoms such as weight loss, fever, and night sweats may be present in the pulmonary location, but physicians should search for disseminated disease. ${ }^{3,30}$ Depending on the extension of the disease, the patient may have dyspnea and low oxygen saturation. Gradually, the pulmonary mass becomes soft and fluctuant, with a purulent center, which could be followed by cavitation. Cavitation may occur in patients with purulent discharge in bronchi, mimicking tuberculosis. Cavitation may also occur in patients with spontaneous drainage through the chest wall, forming a sinus tract. Patients with pulmonary cavitation associated with a chest-wall sinus tract should lead the physician to suspect actinomycosis. ${ }^{24,34,35}$ Patients with pulmonary actinomycosis may also have secondary cutaneous and/or muscular abscesses. ${ }^{42}$

\section{Diagnosis}

Imaging of pulmonary actinomycosis is not specific, and pulmonary actinomycosis is frequently confused with malignancy (mass) or tuberculosis (cavitation). The main CT findings are consolidation, lymph node enlargement, atelectasis, cavitation, ground glass opacity, and pleural effusion. There is no preferential localization in the lung. Pleural involvement, with thickening, effusion, or empyema is associated with about $15 \%-50 \%$ of cases of thoracic actinomycosis. ${ }^{34,41,43,44}$

The gold standard for diagnosing pulmonary actinomycosis is histological examination and bacterial culture of a lung biopsy, obtained by percutaneous biopsy guided by CT scan or by open surgical resection. ${ }^{3,25}$

Bronchoscopy should be performed to exclude malignancy. Simple culture of Actinomyces in BAL, as with sputum, is inappropriate for the diagnosis of pulmonary actinomycosis, except for patients with cavitation, as it may represent colonization. ${ }^{45}$ In patients with pulmonary actinomycosis associated with pleural effusion, it is of importance to note that Actinomyces almost never grow from pleural effusion samples. A. meyeri (nonbranching species with the greater propensity for dissemination) is the more frequent species described in pulmonary involvement cases. ${ }^{7,24,46}$

\section{Current and emerging treatment options}

Patients with pulmonary actinomycosis require prolonged high doses of antimicrobial therapy with beta-lactam antibiotics, and penicillin $\mathrm{G}$, cephalosporin, or amoxicillin are frequently used. For instance, it is recommended to intravenously administer a dose of 18-24 million units per day of penicillin $G$ over 2-6 weeks, followed by oral therapy with penicillin $\mathrm{V}$ or amoxicillin for 6-12 months. ${ }^{1-3}$ Surgery could be required in patients with pulmonary actinomycosis, especially if the patient experienced hemoptysis. ${ }^{47}$ Importantly, in a recent report including 94 patients with pulmonary actinomycosis, half of the patients finally required surgery, especially those who had received cephalosporin (and not penicillin G), suggesting a lower microbiological activity of cephalosporin in comparison with penicillin $\mathrm{G} .{ }^{41}$ Of note, a recent study suggested that patients who undergo surgical intervention have a better outcome, leading to recommendations of surgery for patients with complicated pulmonary actinomycosis (hemoptysis), in patients who do not respond well to high doses of penicillin therapy, or to definitively rule out the diagnosis of lung cancer. ${ }^{47}$ Finally, Kolditz et al, in 2009, published a report of a cohort of 49 patients with pulmonary actinomycosis who were exclusively medically treated. ${ }^{4}$ The authors suggest that the duration of antimicrobials has to be individualized in patients with pulmonary actinomycosis, but that treatment durations less than 3 months in medically treated patients should be avoided, as these patients are at risk for recurrence or local complications. ${ }^{48}$ 


\section{Cervicofacial actinomycosis}

\section{Epidemiology and pathogenesis}

Cervicofacial actinomycosis is the most frequent clinical form of actinomycosis, and "lumpy jaw syndrome", which is associated with odontogenic infection, is the most common clinical manifestation (see "Case 3"), representing approximately $60 \%$ of all reported cases..$^{1-3,49}$ Actinomyces spp. could also be responsible for maxillary osteomyelitis in patients with odontogenic maxillary sinusitis. ${ }^{50}$

A. israelii and A. gerencseriae comprise almost $70 \%$ of cases, but many other species have been described, such as A. meyeri, A. odontolyticus, A. naeslundii, Actinomyces georgiae, Actinomyces pyogenes, or A. viscosus. ${ }^{5}$

Actinomyces are commensals of the human oropharynx, and are particularly prevalent within gingival crevices, tonsillar crypts, periodontal pockets and dental plaques, as well as on carious teeth. Consequently, actinomycosis is mainly considered an endogenous infection that is triggered by a mucosal lesion. ${ }^{1-3}$ The pathophysiology of invasive disease following oral mucosal breach is unknown, but the invariably co-isolated commensals, such as E. corrodens, A. actinomycetemcomitans, or Haemophilus aphrophilus, may inhibit local host defenses, although their exact role is unclear., ${ }^{1,51}$ Cervicofacial actinomycosis could be associated with large abscesses and/or mandibular osteomyelitis with or without sinus tract (see "Case 4"). Finally, cervicofacial actinomycosis can lead to distant organ dissemination, including brain, lungs, and digestive tract. Cervicofacial actinomycosis is a relatively rare condition worldwide, with no predilection for age, race, season, or occupation.

Physiopathological pathways of cervicofacial actinomycosis explain that predisposing conditions include poor oral hygiene (dental caries, gingivitis, infection in erupting secondary teeth) and oral mucosa trauma (dental extraction, gingival trauma, local tissue damage caused by neoplastic condition or irradiation, cervicofacial surgery). Other predisposing factors include male sex, diabetes mellitus, immunosuppression, alcoholism, and malnutrition. ${ }^{1-4,24,51,52}$

Actinomyces spp. are considered to be involved in the pathogenesis of bisphosphonate severe osteonecrosis of the jaw (BONJ), which, until recently, was considered a noninfectious disease. Most patients with osteoporosis receive bisphosphonate therapy. Occurrence of BONJ is associated with duration of bisphosphonate therapy, concomitant use of corticosteroids, and mucosal disruption. The latter may facilitate Actinomyces colonization and invasion of the jaw, as Actinomyces spp. have been detected in biofilm in bone samples from patients with BONJ. ${ }^{53,54}$

\section{Illustrative case reports}

\section{Case 3}

A 43-year-old woman presented with lumpy jaw syndrome following root canal treatment of two right mandibular molar teeth (numbers 45 and 46). Tooth 46 was extracted (Figure 3A), followed by tooth 452 months later (Figure 3B) as mandibular Actinomycosis due to A. naeslundii was diagnosed after surgical debridement and decortication. Prolonged high doses of amoxicillin ( $9 \mathrm{~g}$ /day intravenously over 6 weeks, followed by $6 \mathrm{~g} /$ day orally) was prescribed. One year later, despite continuation of antimicrobial therapy, the patient worsened, with extension of the osteomyelitis to the gonial angle and to the ramus (Figure 3C). New surgery was performed 3 weeks after discontinuation of amoxicillin therapy, and A. naeslundii susceptible to penicillin $\mathrm{G}$ was again found in cultures from perioperative samples. Amoxicillin was prescribed for 14 months, and, after 1 year of follow-up after amoxicillin discontinuation, no relapse was observed.

\section{Case 4}

A 77-year-old woman with past history of breast cancer was admitted 7 years after radiotherapy for left mandibular metastasis with left mandibular pain, buccal-sided bone exposure,
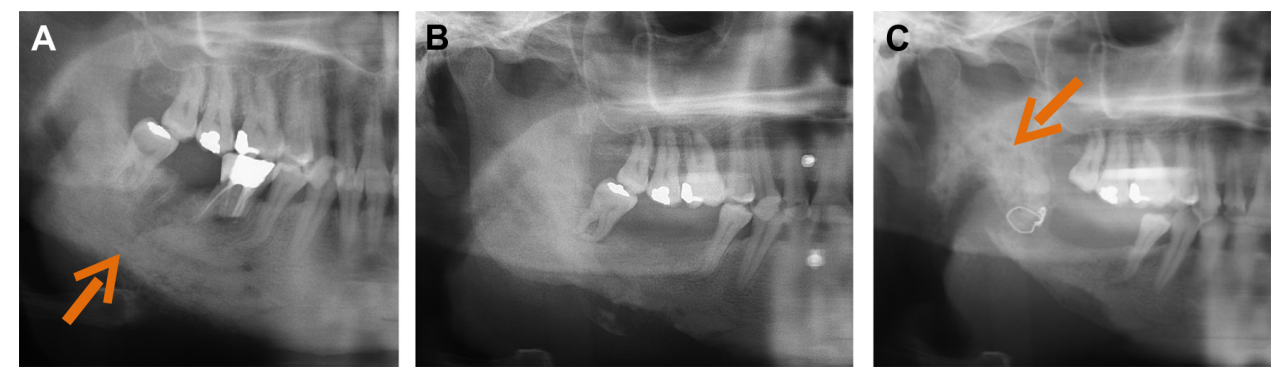

Figure 3 Panoramic dental X-ray showing right mandibular osteomyelitis (“lumpy jaw syndrome”).

Notes: An unfavorable outcome resulted, despite dental extraction of tooth 46 (with arrow showing mandibular thickening with lucencies) (A), followed by tooth 45 2 months later (B). Surgical debridement and decortication were required due to extension of the osteomyelitis to the gonial angle and to the ramus (with arrow showing the typical radiologic aspect of lumpy jaw syndrome) (C). 
and sinus tract (Figure 4). The patient had been receiving long-term trastuzumab therapy with bisphosphonate. As the patient was suspected to have chronic osteomyelitis with actinomycosis, left total hemimandibulectomy was performed. Pathology revealed suppurative osteomyelitis. No sample was sent for the microbiological diagnosis.

\section{Signs and symptoms}

Cervicofacial actinomycosis usually involves tissues surrounding the upper (maxillary expansion of the jaw) or lower mandible, including the mandible itself in approximately $50 \%$ of cases, cheek (15\%), chin (15\%), and submaxillary ramus and angle $(10 \%)$. More rarely, the mandibular joint could be involved. ${ }^{55}$ Typically, the disease presents as a slowly progressive painless indurated mass, evolving into multiple abscesses with draining sinus tracts on the skin surface or oral mucosa, sometimes expressing a typical thick yellow exudate with characteristic sulfur granules. ${ }^{1-3,49,55,56}$ At advanced stages, pain and trismus can occur, linked with mastication muscles infiltration. Acute suppurative forms with rapid abscess formations are less common and are usually febrile and painful. Regional adenopathy is rare. Bone involvement is observed in approximately $10 \%$ of cases.

Although most cases are of odontogenic origin and concern the perimandibular regions, many other locations of primary infections have been described, including the tongue, sinuses, middle ear, larynx, lachrymal pathways, and thyroid gland. ${ }^{57-61}$

Imaging findings are usually noncontributory to the positive diagnosis. Dental panoramic radiograph is mandatory to

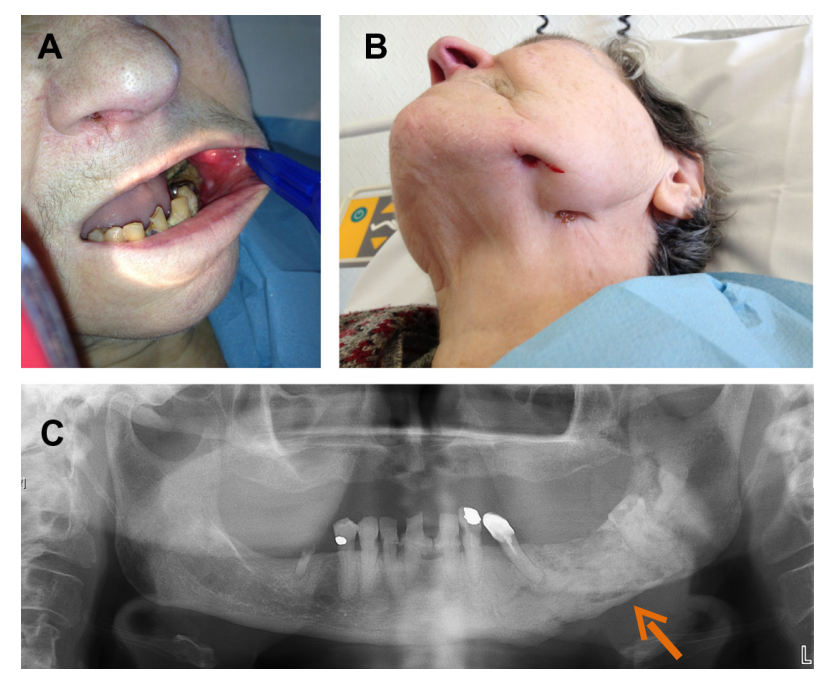

Figure 4 Left mandibular osteomyelitis with bone exposure (A) and sinus tract (B) following left mandibular radiotherapy in a patient receiving long-term bisphosphonate therapy. Panoramic dental $X$-ray shows mandibular lucencies (C). Note: The arrow shows mandibular lucencies. assess apical abscesses, which will require dental avulsions. CT scan and MRI may show a nonspecific involvement of skin and soft tissues, but are useful to assess bone involvement. In case of chronic osteomyelitis, osteolysis is common, with a possible periosteal reaction and intralesional gas. ${ }^{62}$

\section{Diagnosis}

Diagnosis can be difficult, and especially making a distinction between neoplastic conditions, malignant hemopathy, and other cervicofacial infections such as nocardiosis or mycobacterial infections. A nonspecific and mild biological inflammatory syndrome can be found. The gold standard for diagnosing cervicofacial actinomycosis is histological examination and bacterial culture of an abscess or of a suspected bone, if osteomyelitis is suspected. Microbiological cultures of bone samples have to be incubated for 2 weeks, as bacteria frequently reduce their growth capacities in chronic osteomyelitis. ${ }^{63}$ In patients with odontogenic cervicofacial actinomycosis, prescription of oral antimicrobials is common before surgery, leading frequently to false negative results of the cultures. Indeed, taking, for instance, the bacterial diagnosis for patients with prosthetic joint infection, the sensitivity decreased from $76.9 \%$ to $47.8 \%$ to $41.2 \%$ for bone sample culture as the antimicrobial-free interval before surgery decreased from greater than 14 days to 4-14 days, to 0-3 days, respectively. ${ }^{64}$ As a result, in patients with chronic mandibular osteomyelitis suspected to have cervicofacial actinomycosis, disruption of antimicrobials at least 14 days before surgery is mandatory to facilitate the growth of Actinomyces spp. in cultures. In typical cases, ie, especially in patients with lumpy jaw syndrome, Actinomyces spp. have always been targeted by antimicrobial therapy, regardless of the results of microbiological cultures or the result of pathology.

\section{Current and emerging treatment options}

Surgical management can be required for drainage of voluminous abscesses, marsupialization of chronic sinus tracts, excision of recalcitrant fibrotic lesion, and/or debridement of necrotic bone tissue in case of osteomyelitis. ${ }^{1-3,24,49}$ Treatment of dental caries and/or apical abscesses is essential, often necessitating dental avulsions.

No randomized controlled trials have evaluated antibiotic regimens for cervicofacial actinomycosis. Most isolates are susceptible to beta-lactams, and the treatment of choice is a prolonged course of oral amoxicillin. As the penetration of beta-lactams in bone is low $(10 \%-20 \%$ of the administered dose), ${ }^{16}$ intravenous high doses of amoxicillin (up to $200 \mathrm{mg} / \mathrm{kg} /$ day) or penicillin G (up to $24 \mathrm{MIU} /$ day) has to 
be used initially in severe cases. ${ }^{1-3,49}$ Acceptable alternatives include clindamycin, macrolides (erythromycin, clarithromycin, or azithromycin), and doxycycline, which has a better bone penetration. ${ }^{16,65}$ The adjunction of a companion drug such as metronidazole or a beta-lactamase inhibitor is controversial, but may help in these frequent polymicrobial infections. ${ }^{66}$ The traditional prolonged course of up to 6-12 months of treatment can likely be shortened if an optimal surgical resection of infected tissues has been performed, in the absence of bone involvement, and if a satisfactory patient response to treatment is rapidly observed. Indeed, several observations have reported satisfactory cure rates with 4- to 6-week antimicrobial therapy. ${ }^{67,68}$

\section{Extrafacial bone and joint actinomycosis}

Although cervicofacial actinomycosis is the most frequent form of actinomycosis with bone involvement, Actinomyces spp. could also be involved in extrafacial bone and joint infection. Various clinical forms of extrafacial bone and joint actinomycosis have been described: 1) hematogenous spread of localized actinomycosis; 2) contiguous spread of pulmonary actinomycosis to the spine; and 3) polymicrobial bone and joint infection following bone exposition, especially in patients with paraplegia and osteomyelitis of the ischial tuberosity. ${ }^{1-3}$

\section{Epidemiology and pathogenesis}

No data are available on the epidemiology of extrafacial bone and joint actinomycosis. Few case reports have been described in the literature. Concerning hematogenous spread of localized actinomycosis, Brown et al reported a case of hematogenous infection of total hip arthroplasty 9 months after a noninvasive dental procedure with Actinomyces spp. in intraoperative specimen cultures. ${ }^{69}$ Zaman et al reported a case of chronic hematogenous infection due to Actinomyces spp. of prosthetic joint in an intravenous drug user. ${ }^{70}$ Concerning the contiguous spread of pulmonary actinomycosis to the spine, case 2 (detailed in "Respiratory tract actinomycosis") had contiguous spread to the spine, with thoracic spondylitis of the T3 vertebral body, associated with anterior paravertebral abscess (Figure 5A). We report a case of polymicrobial bone and joint infection following bone exposition.

\section{Illustrative case report}

Case 6

A 61-year-old woman with paraplegia was admitted for chronic and extensive back scar $(20 \times 20 \mathrm{~cm})$. MRI showed back soft tissue infiltration, posterior epiduritis, and infection of the L 2 and L4 vertebral bodies (Figure 5B). Laminectomy and excision of necrotic tissue was performed. A. meyeri
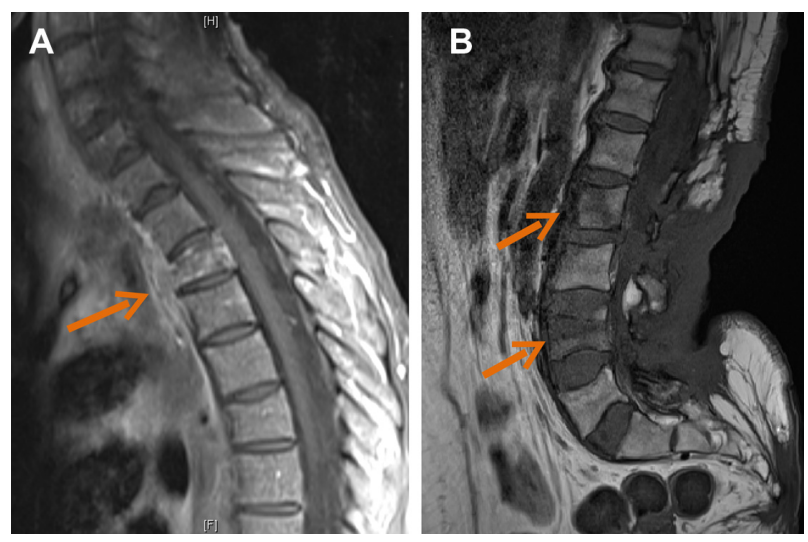

Figure 5 Contrast-enhanced magnetic resonance images showing contiguous spread of pulmonary actinomycosis to the spine (case 2), with thoracic spondylitis of the T3 vertebral body, associated with anterior paravertebral abscess (arrow) (A). Magnetic resonance image showing back soft tissue infiltration, with posterior epiduritis and infection of L2 and L4 vertebral bodies (arrows) in a paraplegic patient with plurimicrobial bone and joint infection following chronic back scar (case 6) (B).

grew in cultures with Escherichia coli and Staphylococcus aureus.

\section{Signs and symptoms}

Most patients with extrafacial bone and joint actinomycosis have insidious onset of the disease, and signs and symptoms are usually similar to those of chronic bone and joint infection. Of note, patients suspected to have actinomycosis bone and joint infection of hematogenous origin usually experience clinical symptoms many months after the suspected bacteremia. ${ }^{70}$

\section{Current and emerging treatment options}

The treatment strategy for extrafacial bone and joint actinomycosis is similar to that of other chronic bone and joint infections. In patients with hematogenous spread of localized actinomycosis, surgery has to be performed if complications are noticed, and if the patient has implant-associated infection (the implant has to be removed). ${ }^{71}$ In patients with contiguous spread of pulmonary actinomycosis to the spine, surgery is required if large abscesses or neurological complications are detected. Finally, in patients with polymicrobial bone and joint infection following bone exposition, surgery (debridement) is often required. In all patients with extrafacial bone and joint actinomycosis, antimicrobial therapy must be based on prolonged high-dose intravenous and then oral beta-lactam therapy, as described in the cervicofacial actinomycosis section.

\section{Genitourinary tract actinomycosis}

Genitourinary tract actinomycosis is the second most frequent clinical form of actinomycosis. The main clinical feature of genitourinary tract actinomycosis is pelvic actinomycosis in 
women using an intrauterine device (IUD). ${ }^{71-74}$ However, other clinical presentations have been described, such as primary bladder actinomycosis and testicular actinomycosis. ${ }^{75}$

\section{Epidemiology and pathogenesis}

A. israelii is one of the most common species involved in pelvic actinomycosis. Colonization of the female genital tract by Actinomyces spp. is greatly promoted by the use of an IUD. ${ }^{76,77}$ Moreover, IUDs have a traumatizing effect on endothelium by causing erosion, which may facilitate actinomycosis invasion. Actinomycosis IUD-associated infection is infrequent, but is clearly associated with the duration of the IUD use, hence it is recommended that an IUD be replaced every 5 years. $^{76,77}$ There are no data comparing copper, hormonal, or inert IUDs in terms of the risk of actinomycosis. During IUD-associated actinomycosis, abscess formation is frequently observed in the genital tract, and creates dense adhesions with contiguous structures such as small bowel, promoting extensive fibrosis, fistulas, and peritonitis. $^{72-74}$

The pathogenesis of primary bladder actinomycosis is unclear, but could be due to cryptic locations, and usually mimics bladder carcinoma. The lesion may invade adjacent organs such as the uterus or the sigmoid colon. The diagnosis of primary bladder actinomycosis is of crucial importance, as it may avoid large surgical resection for suspected carcinoma. ${ }^{75}$

\section{Illustrative case reports}

Case 7

A 59-year-old woman with appendectomy as past medical history was admitted for acute peritonitis with fever. CT scan revealed an IUD, which had not been changed for 20 years, peritoneal effusion, and heterogeneous pelvic mass (Figure 6). Coelioscopy showed intraperitoneal pus and a right pelvic mass, with inflammation of the adherent small intestine, without evidence of perforation. The IUD was removed, as salpingitis and endometritis were also found. As actinomycosis was suspected, intravenous high doses of amoxicillin were started. Streptococcus spp., Bacteroides fragilis, and Gardnerella vaginalis were found in cultures. Actinomyces spp. did not grow in cultures. Pathology found inflammation with sulfur granules suggesting pelvic actinomycosis. The patient responded well to prolonged oral amoxicillin therapy.

\section{Signs and symptoms}

Symptoms of patients with pelvic IUD-associated actinomycosis may mimic symptoms of gynecological malignant tumors, or uterine myoma or adenomyosis, by presenting as
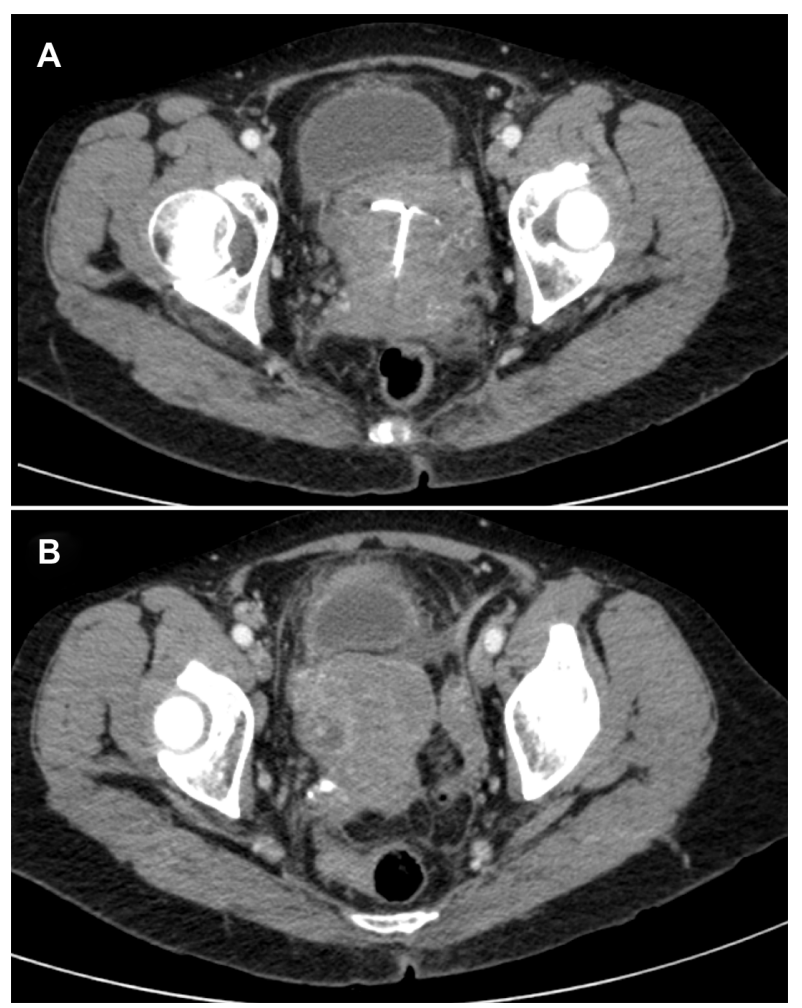

Figure 6 Abdominal computed tomography scan showing peritoneal effusion and heterogeneous pelvic mass surrounding an intrauterine device $(\mathbf{A})$, with abscesses (B) corresponding with pelvic actinomycosis.

a genital mass without fever. ${ }^{72-74}$ Symptoms could be lower abdominal pain, constipation, and/or vaginal discharge. The duration of symptoms is usually 2 months at the time of diagnosis. Fever is usually not observed, except if a complication such as peritonitis occurs.

From blood test results, the white cell count is usually elevated with a high neutrophil count percentage and elevated C-reactive protein. Carbohydrate antigen 125, which can be associated with ovarian cancer, could also be elevated during pelvic actinomycosis. ${ }^{72-74}$

CT scan usually reveals a pelvic mass with a mean size of 6-7 cm and with cystic lesions. A tubo-ovarian abscess strongly suggests pelvic actinomycosis, whereas some patients present with radiological findings suggesting malignant tumors. Lymphadenopathy is associated in 50\% of cases. ${ }^{72-74}$

Primary bladder actinomycosis can mimic bladder carcinoma, with macroscopic hematuria associated with thickening of the bladder wall. ${ }^{75,76}$

\section{Diagnosis}

Women carrying an IUD for over 5 years and presenting with a pelvic mass have a high index of suspicion for IUD-related actinomycosis. However, IUD-related actinomycosis has 
also been found within several months of IUD insertion. ${ }^{72-74}$ In patients suspected to have IUD-related actinomycosis, samples from surgical IUD removal, especially those containing pus, are required for bacterial cultures. Pathology must be done in patients with genitourinary tract masses showing sulfur granules and excluding gynecological malignant tumors.

IUD-related actinomycosis has to be distinguished from IUD colonization by Actinomyces spp. IUDs are frequently colonized by Actinomyces spp. and no antimicrobial treatment is required for asymptomatic women who systematically change their IUD in the 5 years following insertion. ${ }^{76,77}$

In patients suspected to have primary bladder actinomycosis, guided biopsy should help toward diagnosis before performing surgical resection. ${ }^{74,75}$

\section{Current and emerging treatment options}

Removal of the IUD is crucial in patients with IUD-associated actinomycosis. ${ }^{74,78}$ Open surgical resection, often required for the definite diagnosis of genitourinary tract actinomycosis, facilitates the cure, but may be mutilating, especially if hysterectomy or bladder resection is performed..$^{72-77}$

Antimicrobial therapy is the main treatment for genitourinary tract actinomycosis. Patients with genitourinary tract actinomycosis usually receive several weeks of intravenous high doses of a beta-lactam, followed by oral therapy for 2-6 months. There are no extensive data on the duration of antimicrobial therapy in such patients, but the duration of antimicrobials should probably be reduced in patients with extensive surgical resection of a small genital mass. ${ }^{72-75}$

\section{Digestive tract actinomycosis}

Actinomyces spp. are saprophyte organisms of the mouth and digestive tract; actinomycosis of each part of the digestive tract has been previously described.

\section{Epidemiology and pathogenesis}

A. israelii is one of the most common species involved in abdominal actinomycosis. As with IUD-associated actinomycosis, a mucosal trauma causing erosion may facilitates actinomycosis invasion and infection. Digestive tract actinomycosis, as with Actinomyces spp. infections in other locations, may also mimic malignancy.

Esophageal actinomycosis is infrequent, with only around 20 cases described in the literature. Patients with esophageal actinomycosis are usually immunosuppressed by malignancy,
HIV, or solid transplant. Most patients present with ulceration, and a few had perforation, an abscess, and sinus tract. ${ }^{79}$

Appendix, cecum, and colon are the most common abdominal sites of actinomycosis, which can occur weeks to years after gastrointestinal mucosa disruption, and for which previous surgery such as for appendicitis or colonic diverticulitis with perforation are predisposing factors. ${ }^{1-3}$ Abdominal wall involvement with fistula may complicate abdominal actinomycosis (see "Case 8").

Actinomycosis of the liver, the biliary tract, and the pancreas has also been described. ${ }^{80,81}$ Liver involvement mimicking malignancy or presenting as an abscess could be associated with digestive tract disease such as colonic diverticular disease. Pancreatic actinomycosis has been described in patients with pancreatic stents. ${ }^{81}$

\section{Illustrative case report \\ Case 8}

A 78-year-old man had a past history of endarterectomy, open surgery for deep gastric ulcer, abdominal wall implant for eventration, and cholangiocarcinoma. Following the surgery for cholangiocarcinoma, the patient experienced chronic enterocutaneous fistula. CT scan showed enterocutaneous fistula (Figure 7A) and multiple large abdominal abscesses (Figure 7B). Surgical exploration revealed liquefaction of the wall implant. E. coli, Streptococcus anginosus, and Enterococcus spp. grew in cultures, but Actinomyces spp. did not, whereas pathology found aggregates of Actinomyces, typical sulfur granules, and filamentous bacteria (Figure 8). A prolonged antimicrobial therapy with amoxicillin cured the patient.

\section{Signs and symptoms}

Signs and symptoms of patients with digestive tract actinomycosis depend on the anatomical location of the disease. Patients with ulcerative involvement of the esophagus mainly have dysphagia; patients with appendix, cecum, or colon actinomycosis frequently have abdominal pain with a palpable mass; patients with liver and biliary tract actinomycosis frequently have right upper quadrant pain and icterus. ${ }^{80,81}$

\section{Diagnosis}

As Actinomyces spp. are commensals of the digestive tract, pathology is crucial for the diagnosis of digestive tract actinomycosis, as Actinomyces spp. can be expected to contaminate digestive tract biopsies. 

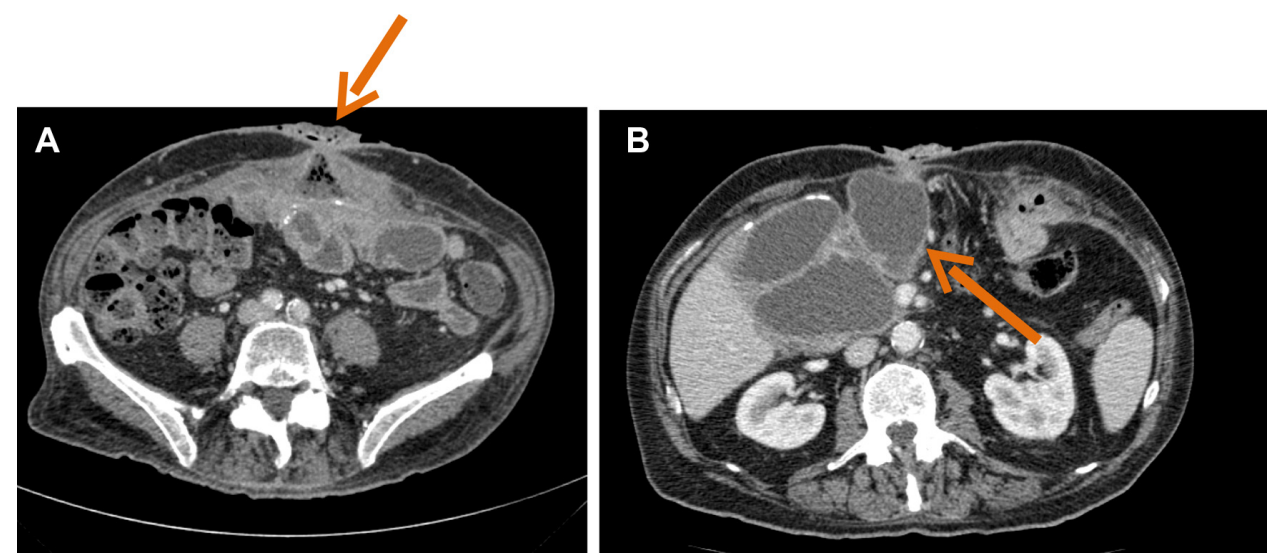

Figure 7 Abdominal computed tomography scan of a patient with evidence of actinomycosis on pathology. Notes: Enterocutaneous fistula (arrow) (A) was associated with large intra-abdominal abscess (arrow) (B).

\section{Current and emerging treatment options}

As with other forms of actinomycosis, prolonged antimicrobial therapy is required for the treatment of digestive tract actinomycosis. Surgery is required in complicated cases, such as in patients with fistula and cell wall involvement. ${ }^{80,81}$
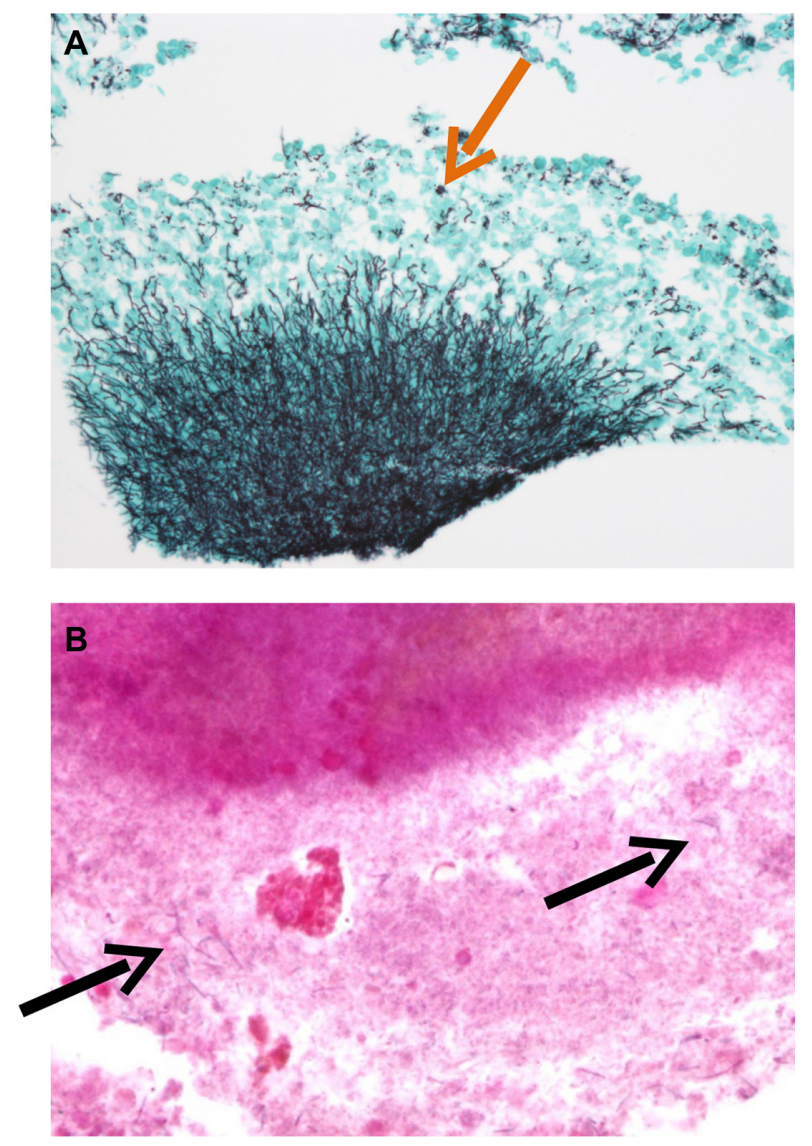

Figure 8 Pathology of a suppurative lesion in a patient with an abdominal wall implant.

Notes: Aggregates of Actinomyces spp. and sulfur granules (arrow) after silver staining (A); filamentous bacteria (arrows) after Gram staining (B).

\section{Central nervous system actinomycosis Epidemiology and pathogenesis}

Actinomyces spp. are mainly involved in brain abscess, but meningitis, meningoencephalitis, epidural abscess, and subdural empyema have also been described. The central nervous system involvement occurs hematogenously from the lung or contiguously from a cervicofacial actinomycosis or following a penetrating head injury. Central nervous system actinomycosis is usually polymicrobial. ${ }^{82-84}$

\section{Illustrative case report \\ Case 9}

A 50-year-old man with alcohol and tobacco abuse was admitted for aphasia and left hemiparesis. CT scan revealed a right temporoparietal lesion with perilesional edema (Figure 9). Stereotaxic puncture revealed pus with Fusobacterium nucleatum and A. meyeri in cultures.

\section{Signs and symptoms}

Symptoms are unspecific, and patients frequently experience focal weakness, sensory losses, and seizures. A contrastenhanced, thick-walled ring lesion with secondary edema and vascular congestion is usually observed. ${ }^{1-3,82-84}$

\section{Diagnosis}

The diagnosis is mainly based on stereotaxic aspiration of pus, revealing Actinomyces spp. in cultures and sulfur granules in pathology. ${ }^{1-3,82-84}$

\section{Current and emerging treatment options}

The treatment of actinomycosis brain abscess requires prolonged antimicrobial therapy after pus aspiration. ${ }^{1-3,82-84}$ 


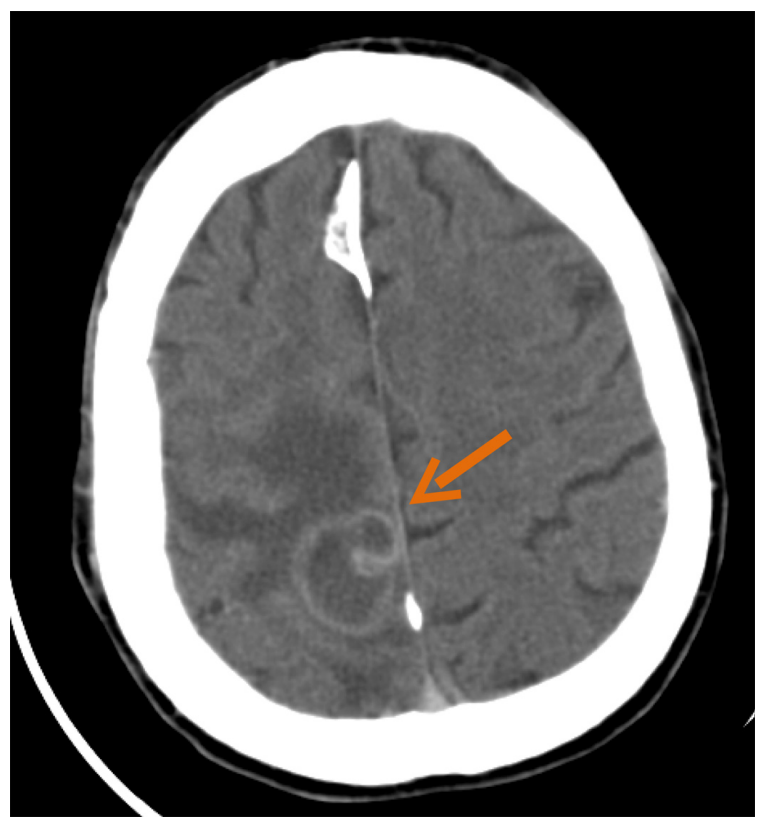

Figure 9 Computed tomography scan revealing a right temporoparietal abscess (arrow) with perilesional edema.

Note: Actinomyces meyeri was found in cultures.

\section{Cutaneous actinomycosis}

\section{Epidemiology and pathogenesis}

Primary skin and soft-tissue actinomycosis is poorly described. Skin disruption may facilitate invasion of Actinomyces spp.

\section{Illustrative case report \\ Case 10}

A 65-year-old obese man was admitted for left facial cellulitis with left pinna edema following ear acupuncture. MRI revealed abscess of the left earlobe (Figure 10).

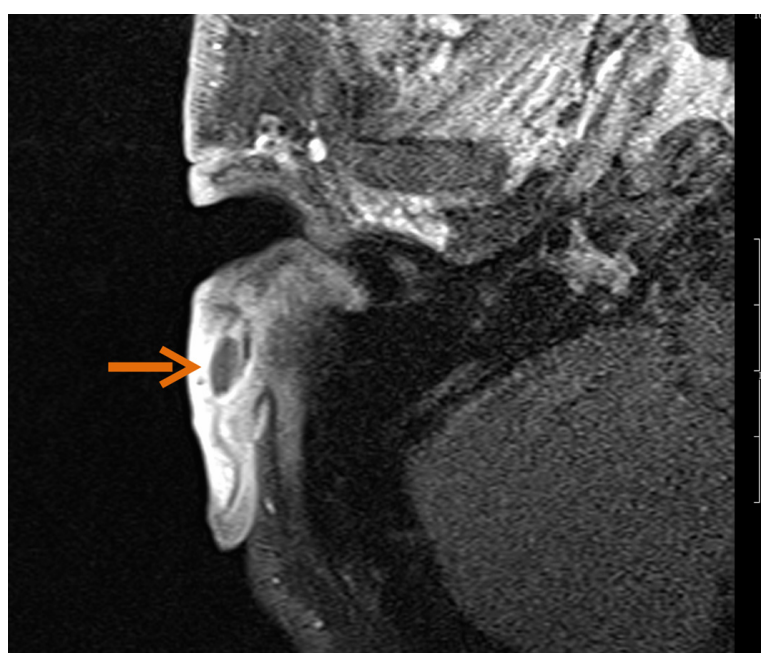

Figure 10 Contrast-enhanced magnetic resonance image of the left ear of a patient with an abscess (arrow) due to Actinomyces spp. earlobe infection following acupuncture.
Surgical drainage of pus revealed Actinomyces spp. in cultures. The outcome was favorable after 6 weeks of intravenous high doses of amoxicillin, followed by oral therapy for 4 months.

\section{Signs and symptoms}

Most patients have progressive skin and soft-tissue inflammation, which can become an abscess or cold mass, or nodular lesions with fistulas that need to be differentiated from chronic inflammatory skin disease, cutaneous mycobacterial infections, and sporotrichosis. ${ }^{85,86}$

\section{Current and emerging treatment options}

In patients with primary skin and soft-tissue actinomycosis, abscesses have to be drained and prolonged antimicrobial therapy is required to achieve cure. ${ }^{85,86}$

\section{Implications for enhanced patient care}

The main implication for physicians in enhancing the care of patients with actinomycosis is to be aware of the different clinical forms of actinomycosis. Indeed, the diagnosis is crucial for an accurate diagnosis, by using specific culture media that allow the growth of Actinomyces spp. and looking for sulfur granules.

Surgery should be discussed in complicated cases, but the cornerstone of treatment is prolonged antimicrobial therapy with a beta-lactam such as penicillin or amoxicillin.

Preventive measures are required to limit the occurrence of the disease. Reduction of alcohol abuse and improvement of dental hygiene may limit the occurrence of pulmonary, cervicofacial, and central nervous system actinomycosis. IUDs should be changed every 5 years in women, to limit the occurrence of pelvic actinomycosis.

\section{Conclusion}

Actinomycosis is a rare chronic disease caused by Actinomyces spp., anaerobic Gram-positive bacteria that normally colonize the human mouth and digestive and genital tracts. Physicians have to be aware of typical clinical presentations (such as cervicofacial actinomycosis following dental focus of infection, pelvic actinomycosis in women with an IUD, and pulmonary actinomycosis in smokers with poor dental hygiene), but also must be aware that actinomycosis may mimic the malignancy process in various anatomical sites. Bacterial cultures and pathology are the cornerstones of diagnosis and require particular attention to prevent misdiagnosis. Prolonged bacterial cultures in anaerobic 
conditions are necessary for identification of the bacterium, and typical microscopic findings include necrosis with yellowish sulfur granules and filamentous Gram-positive fungal-like pathogen. Patients with actinomycosis require prolonged (6- to 12-month) high doses of penicillin G or amoxicillin, but the duration of antimicrobial therapy could likely be reduced ( 3 months) for patients in whom optimal surgical resection of infected tissues has been performed. Specific preventive measures (reduction of alcohol abuse, dental hygiene, change of IUD every 5 years) may limit the occurrence of actinomycosis.

\section{Acknowledgments}

The authors acknowledge Dr Frédérique Lebreton, pathologist, and our colleagues at the Lyon Bone and Joint Infection Study Group, as follows. Physicians: Tristan Ferry, Thomas Perpoint, André Boibieux, François Biron, Florence Ader, Judith Karsenty, Florent Valour, Fatiha Daoud, Johanna Lippman, Evelyne Braun, Marie-Paule Vallat, Patrick Miailhes, Christian Chidiac, and Dominique Peyramond. Surgeons: Sébastien Lustig, Philippe Neyret, Elvire Servien, Olivier Reynaud, Vincent Villa, Olivier Guyen, Jean-Baptiste Bérard, Olivier Cantin, Frédéric Dalat, Romain Desmarchelier, Michel-Henry Fessy, Cédric Barrey, Francesco Signorelli, Pierre Breton, Ali Mojallal, Fabien Boucher, and Hristo Shipkov. Microbiologists: Frederic Laurent, François Vandenesch, Jean-Philippe Rasigade, and Céline Dupieux. Nuclear medicine specialists: Isabelle Morelec, Marc Janier, and Francesco Giammarile; PK/PD specialists: Michel Tod, Marie-Claude Gagnieu, and Sylvain Goutelle. Clinical research assistant: Eugénie Mabrut.

\section{Disclosure}

The authors report no conflicts of interest in this work.

\section{References}

1. Wong VK, Turmezei TD, Weston VC. Actinomycosis. BMJ. 2011;343:d6099.

2. Smego RA Jr, Foglia G. Actinomycosis. Clin Infect Dis. 1998;26(6): 1255-1261.

3. Mandell GL, Bennett JE, Dolin R, editors. Mandell, Douglas, and Bennett's Principles and Practice of Infectious Diseases. 7th ed. Philadelphia, PA: Churchill Livingstone Elsevier; 2010.

4. Schaal KP, Lee HJ. Actinomycete infections in humans - a review. Gene. 1992;115(1-2):201-211.

5. Pulverer G, Schütt-Gerowitt H, Schaal KP. Human cervicofacial actinomycoses: microbiological data for 1997 cases. Clin Infect Dis. 2003;37(4):490-497.

6. Eng RH, Corrado ML, Cleri D, Cherubin C, Goldstein EJ. Infections caused by Actinomyces viscosus. Am J Clin Pathol. 1981;75(1):113-116.

7. Fazili T, Blair D, Riddell S, Kiska D, Nagra S. Actinomyces meyeri infection: case report and review of the literature. J Infect. 2012;65(4):357-361.
8. Coleman RM, Georg LK, Rozzell AR. Actinomyces naeslundii as an agent of human actinomycosis. Appl Microbiol. 1969;18(3): $420-426$.

9. Cone LA, Leung MM, Hirschberg J. Actinomyces odontolyticus bacteremia. Emerg Infect Dis. 2003;9(12):1629-1632.

10. Sabbe LJ, Van De Merwe D, Schouls L, Bergmans A, Vaneechoutte M, Vandamme P. Clinical spectrum of infections due to the newly described Actinomyces species A. turicensis, A. radingae, and A. europaeus. J Clin Microbiol. 1999;37(1):8-13.

11. Clarridge JE 3rd, Zhang Q. Genotypic diversity of clinical Actinomyces species: phenotype, source, and disease correlation among genospecies. J Clin Microbiol. 2002;40(9):3442-3448.

12. Felz MW, Smith MR. Disseminated actinomycosis: multisystem mimicry in primary care. South Med J. 2003;96(3):294-299.

13. Jordan HV, Kelly DM, Heeley JD. Enhancement of experimental actinomycosis in mice by Eikenella corrodens. Infect Immun. 1984;46(2):367-371.

14. Glahn M. Cervico-facial actinomycosis; etiology and diagnosis. Acta Chir Scand. 1954;108(2-3):183-192.

15. Holm P. Studies on the aetiology of human actinomycosis. II. Do the other microbes of actinomycosis possess virulence? Acta Pathol Microbiol Scand. 1951;28(4):391-406.

16. Bennhoff DF. Actinomycosis: diagnostic and therapeutic considerations and a review of 32 cases. Laryngoscope. 1984;94(9):1198-1217.

17. Lewis R, McKenzie D, Bagg J, Dickie A. Experience with a novel selective medium for isolation of Actinomyces spp. from medical and dental specimens. J Clin Microbiol. 1995;33(6):1613-1616.

18. Ng LS, Sim JH, Eng LC, Menon S, Tan TY. Comparison of phenotypic methods and matrix-assisted laser desorption ionisation time-of-flight mass spectrometry for the identification of aero-tolerant Actinomyces spp. isolated from soft-tissue infections. Eur J Clin Microbiol Infect Dis. 2012;31(8):1749-1752.

19. Miller PH, Wiggs LS, Miller JM. Evaluation of API An-IDENT and RapID ANA II systems for identification of Actinomyces species from clinical specimens. J Clin Microbiol. 1995;33(2):329-330.

20. Garner O, Mochon A, Branda J, et al. Multi-centre evaluation of mass spectrometric identification of anaerobic bacteria using the VITEK ${ }^{\circledR}$ MS system. Clin Microbiol Infect. Epub July 4, 2013.

21. Hall V, Talbot PR, Stubbs SL, Duerden BI. Identification of clinical isolates of Actinomyces species by amplified 16S ribosomal DNA restriction analysis. J Clin Microbiol. 2001;39(10):3555-3562.

22. Xia T, Baumgartner JC. Occurrence of Actinomyces in infections of endodontic origin. J Endod. 2003;29(9):549-552.

23. Hall V. Actinomyces - gathering evidence of human colonization and infection. Anaerobe. 2008;14:1-7.

24. Brown JR. Human actinomycosis. A study of 181 subjects. Hum Pathol. 1973;4(3):319-330.

25. Mabeza GF, Macfarlane J. Pulmonary actinomycosis. Eur Respir J. 2003;21(3):545-551.

26. Pine L. Recent developments on the nature of the anaerobic actinomycetes. Ann Soc Belg Med Trop (1920). 1963;43:247-257.

27. Hotchi M, Schwarz J. Characterization of actinomycotic granules by architecture and staining methods. Arch Pathol. 1972;93(5):392-400.

28. Heffner JE. Pleuropulmonary manifestations of actinomycosis and noardiosis. Semin Respir Infect. 1988;3:352-361.

29. Smith AJ, Hall V, Thakker B, Gemmell CG. Antimicrobial susceptibility testing of Actinomyces species with 12 antimicrobial agents. $J$ Antimicrob Chemother. 2005;56(2):407-409.

30. Bates M, Cruickshank G. Thoracic actinomycosis. Thorax. 1957; 12(2):99-124.

31. Apothéloz C, Regamey C. Disseminated infection due to Actinomyces meyeri: case report and review. Clin Infect Dis. 1996;22(4):621-625.

32. Chaudhry SI, Greenspan JS. Actinomycosis in HIV infection: a review of a rare complication. Int J STD AIDS. 2000;11(6):349-355.

33. Cohen RD, Bowie WR, Enns R, Flint J, Fitzgerald JM. Pulmonary actinomycosis complicating infliximab therapy for Crohn's disease. Thorax. 2007;62(11):1013-1014. 
34. Cheon JE, Im JG, Kim MY, Lee JS, Choi GM, Yeon KM. Thoracic actinomycosis: CT findings. Radiology. 1998;209(1):229-233.

35. Han JY, Lee KN, Lee JK, et al. An overview of thoracic actinomycosis: CT features. Insights Imaging. 2013;4(2):245-252.

36. Bartlett AH, Rivera AL, Krishnamurthy R, Baker CJ. Thoracic actinomycosis in children: case report and review of the literature. Pediatr Infect Dis J. 2008;27(2):165-169.

37. Chouabe S, Perdu D, Deslée G, Milosevic D, Marque E, Lebargy F. Endobronchial actinomycosis associated with foreign body: four cases and a review of the literature. Chest. 2002;121(6):2069-2072.

38. Maki K, Shinagawa N, Nasuhara Y, et al. Endobronchial actinomycosis associated with a foreign body - successful short-term treatment with antibiotics -. Intern Med. 2010;49(13):1293-1296.

39. Yoshihama K, Kato Y, Baba Y. Vocal cord actinomycosis mimicking a laryngeal tumor. Case Rep Otolaryngol. 2013;2013:361986.

40. Ferry T, Buiret G, Pignat JC, Chidiac C. Laryngeal actinomycosis mimicking relapse of laryngeal carcinoma in a 67-year-old man. BMJ Case Rep. 2012;2012.

41. Kim SR, Jung LY, Oh IJ, et al. Pulmonary actinomycosis during the first decade of 21st century: cases of 94 patients. BMC Infect Dis. 2013;13(1):216.

42. Liaudet L, Erard P, Kaeser P. Cutaneous and muscular abscesses secondary to Actinomyces meyeri pneumonia. Clin infect Dis. 1996;22:185-186.

43. Kim TS, Han J, Koh WJ, et al. Thoracic actinomycosis: CT features with histopathologic correlation. AJR Am J Roentgenol. 2006;186(1): 225-231.

44. Pérez-Castrillón J, Gonzalez-Castâneda C, del Campo-Matias F, Bellido-Casado J, Diaz G. Empyema necessitatis due to Actinomyces odontolyticus. Chest. 1996;111(4):1144.

45. Nair PN, Brundin M, Sundqvist G, Sjögren U. Building biofilms in vital host tissues: a survival strategy of Actinomyces radicidentis. Oral Surg Oral Med Oral Pathol Oral Radiol Endod. 2008;106(4):595-603.

46. Colmegna I, Rodriguez-Barradas M, Rauch R, Clarridge J, Young EJ. Disseminated Actinomyces meyeri infection resembling lung cancer with brain metastases. Am J Med Sci. 2003;326(3):152-155.

47. Song JU, Park HY, Jeon K, Um SW, Kwon OJ, Koh WJ. Treatment of thoracic actinomycosis: a retrospective analysis of 40 patients. Ann Thorac Med. 2010;5(2):80-85.

48. Kolditz M, Bickhardt J, Matthiessen W, Holotiuk O, Höffken G, Koschel D. Medical management of pulmonary actinomycosis: data from 49 consecutive cases. J Antimicrob Chemother. 2009;63(4):839-841.

49. Oostman O, Smego RA. Cervicofacial actinomycosis diagnosis and management. Curr Infect Dis Rep. 2005;7(3):170-174.

50. Saibene AM, Di Pasquale D, Pipolo C, Felisati G. Actinomycosis mimicking sinonasal malignant disease. BMJ Case Rep. 2013;2013.

51. Holm P. Studies on the aetiology of human actinomycosis. Acta Pathol Microbiol Scand Suppl. 1951;91:172-173.

52. Weese WC, Smith IM. A study of 57 cases of actinomycosis over a 36-year period. A diagnostic 'failure' with good prognosis after treatment. Arch Intern Med. 1975;135(12):1562-1568.

53. Naik NH, Russo TA. Bisphosphonate-related osteonecrosis of the jaw: the role of actinomyces. Clin Infect Dis. 2009;49(11):1729-1732.

54. Gallay L, Bodard AG, Chidiac C, Ferry T. Bilateral bisphosphonate-related osteonecrosis of the jaw with left chronic infection in an 82-year-old woman. BMJ Case Rep. 2013;2013.

55. Schaal KP, Beaman BL. Clinical significance of actinomycetes. In: Goodfellow M, Mordarski M, Williams ST, editors. The Biology of the Actinomycetes. New York: Academic Press; 1983:389.

56. Lerner PI. The lumpy jaw. Cervicofacial actinomycosis. Infect Dis Clin North Am. 1988;2(1):203-220.

57. Atespare A, Keskin G, Erçin C, Keskin S, Camcioglu A. Actinomycosis of the tongue: a diagnostic dilemma. J Laryngol Otol. 2006;120(8):681-683.
58. Kalioras V, Thanos L, Mylona S, Pomoni M, Batakis N. Scalp actinomycosis mimicking soft tissue mass. Dentomaxillofac Radiol. 2006;35(2):117-118.

59. Kullar PJ, Yates P. Actinomycosis of the middle ear. J Laryngol Otol. 2013;127(7):712-715.

60. Sánchez Legaza E, Cercera Oliver C, Miranda Caravallo JI. Actinomycosis of the paranasal sinuses. Acta Otorrinolaringol Esp. 2013;64(4):310 311. English, Spanish.

61. Vorasubin $\mathrm{N}, \mathrm{Wu} \mathrm{AW}, \mathrm{Day} \mathrm{C}, \mathrm{Suh}$ JD. Invasive sinonasal actinomycosis: case report and literature review. Laryngoscope. 2013; 123(2):334-338.

62. Sasaki Y, Kaneda T, Uyeda JW, et al. Actinomycosis in the mandible: CT and MR findings. AJNR Am J Neuroradiol. 2014;35(2): 390-394.

63. Schäfer P, Fink B, Sandow D, Margull A, Berger I, Frommelt L. Prolonged bacterial culture to identify late periprosthetic joint infection: a promising strategy. Clin Infect Dis. 2008;1;47(11):1403-1409.

64. Trampuz A, Piper KE, Jacobson MJ, et al. Sonication of removed hip and knee prostheses for diagnosis of infection. $N$ Engl $J$ Med. 2007;357(7):654-663.

65. Landersdorfer CB, Bulitta JB, Kinzig M, Holzgrabe U, Sörgel F. Penetration of antibacterials into bone: pharmacokinetic, pharmacodynamic and bioanalytical considerations. Clin Pharmacokinet. 2009;48(2):89-124.

66. Tanaka-Bandoh K, Watanabe K, Kato N, Ueno K. Susceptibilities of Actinomyces species and Propionibacterium propionicus to antimicrobial agents. Clin Infect Dis. 1997;25 Supp1 2:S262-S263.

67. Moghimi M, Salentijn E, Debets-Ossenkop Y, Karagozoglu K, Forouzanfar T. Treatment of cervicofacial actinomycosis: a report of 19 cases and review of literature. Med Oral Patol Oral Cir Bucal. 2013;18(4):e627-e632.

68. Sudhakar SS, Ross JJ. Short-term treatment of actinomycosis: two cases and a review. Clin Infect Dis. 2004;38(3):444-447.

69. Brown ML, Drinkwater CJ. Hematogenous infection of total hip arthroplasty with Actinomyces following a noninvasive dental procedure. Orthopedics. 2012;35(7):e1086-e1089.

70. Zaman R, Abbas M, Burd E. Late prosthetic hip joint infection with Actinomyces israelii in an intravenous drug user: case report and literature review. J Clin Microbiol. 2002;40(11):4391-4392.

71. Lew DP, Waldvogel FA. Osteomyelitis. Lancet. 2004;364(9431): 369-379.

72. Garner JP, Macdonald M, Kumar PK. Abdominal actinomycosis. Int J Surg. 2007;5(6):441-448.

73. Sung HY, Lee IS, Kim SI, et al. Clinical features of abdominal actinomycosis: a 15-year experience of a single institute. $J$ Korean Med Sci. 2011;26(7):932-937.

74. Choi MH, Hong DG, Seong WJ, Lee YS, Park IS. Pelvic actinomycosis confirmed after surgery: single center experience. Arch Gynecol Obstet. 2010;281(4):651-656.

75. Bae JH, Song R, Lee A, Park JS, Kim MR. Computed tomography for the preoperative diagnosis of pelvic actinomycosis. J Obstet Gynaecol Res. 2011;37(4):300-304.

76. Al-Kadhi S, Venkiteswaran KP, Al-Ansari A, Shamsudini A, Al-Bozom I, Kiliyanni AS. Primary vesical actinomycosis: a case report and literature review. Int J Urol. 2007;14(10):969-971.

77. Westhoff C. IUDs and colonization or infection with Actinomyces. Contraception. 2007;75(Suppl 6):S48-S50.

78. Bonacho I, Pita S, Gómez-Besteiro MI. The importance of the removal of the intrauterine device in genital colonization by actinomyces. Gynecol Obstet Invest. 2001;52(2):119-123.

79. Abdalla J, Myers J, Moorman J. Actinomycotic infection of the oesophagus. J Infect. 2005;51(2):E39-E43.

80. Joshi V, Koulaouzidis A, McGoldrick S, Tighe M, Tan C. Actinomycotic liver abscess: a rare complication of colonic diverticular disease. Ann Hepatol. 2010;9(1):96-98. 
81. Acevedo F, Baudrand R, Letelier LM, Gaete P. Actinomycosis: a great pretender. Case reports of unusual presentations and a review of the literature. Int J Infect Dis. 2008;12(4):358-362.

82. Roth J, Ram Z. Intracranial infections caused by Actinomyces species. World Neurosurg. 2010;74(2-3):261-262.

83. Haggerty CJ, Tender GC. Actinomycotic brain abscess and subdural empyema of odontogenic origin: case report and review of the literature. J Oral Maxillofac Surg. 2012;70(1):e210-e213.
84. Na KY, Jang JH, Sung JY, Kim YW, Park YK. Actinomycotic brain abscess developed 10 years after head trauma. Korean J Pathol. 2013;47(1):82-85.

85. Khandelwal R, Jain I, Punia S, et al. Primary actinomycosis of the thigh - a rare soft tissue infection with review of literature. JRSM Short Rep. 2012;3(4):24.

86. Ozaras R, Mert A. Clinical image: primary actinomycosis of the hand. Arthritis Rheum. 2010;62(2):419.

\section{Publish your work in this journal}

Infection and Drug Resistance is an international, peer-reviewed openaccess journal that focuses on the optimal treatment of infection (bacterial, fungal and viral) and the development and institution of preventive strategies to minimize the development and spread of resistance. The journal is specifically concerned with the epidemiology of antibiotic

\section{Dovepress}

resistance and the mechanisms of resistance development and diffusion in both hospitals and the community. The manuscript management system is completely online and includes a very quick and fair peerreview system, which is all easy to use. Visit http://www.dovepress.com/ testimonials.php to read real quotes from published authors.

Submit your manuscript here: http://www.dovepress.com/infection-and-drug-resistance-journal 